\title{
The effects of ultraviolet B (UV-B) irradiation on color quality and decay rate of Capia pepper during postharvest storage
}

\author{
Mehmet Ufuk KASIM ${ }^{1}$, Rezzan KASIM ${ }^{2 *}$
}

\begin{abstract}
The current study demonstrates that the ultraviolet-B (UV-B) irradiation not only helps in improvement of the red color of the peppers but also reduces their rate of decay. The Capia peppers were harvested at their full red ripe stage and subjected to the UV-B treatment at doses $4.46 \mathrm{~kJ} \mathrm{~m}^{-2}$ (UV-B 15) and $8.93 \mathrm{~kJ} \mathrm{~m}^{-2}$ (UV-B 30). Post irradiation, the peppers were packaged and stored at $5 \pm 1{ }^{\circ} \mathrm{C}$ temperature with $90-95 \% \mathrm{RH}$ for 49 days. The UV-B treated group showed lower $\mathrm{L}^{*}$ values, but higher $\mathrm{a}^{*}$ and $\mathrm{h}^{\circ}$ values as compared to the control group. Therefore, it was found that both the doses of UV-B radiations could enhance the quality of red color of the peppers. However, the lower dose $\left(4.46 \mathrm{~kJ} \mathrm{~m}^{-2}\right)$ was found to be optimal for reducing the decay rate of the peppers. The UV-B 30 peppers showed highest respiration rate, electrolyte leakage, total soluble solids, and the amount of weight loss.
\end{abstract}

Keywords: pepper; Capia; cold storage; UV-B; light.

Practical Application: UV-B treatments improves quality both increasing color and decreasing decay rate of red pepper stored at low temperature, without any symptoms of chilling injury.

\section{Introduction}

Capia pepper is the second most widely produced variety of peppers in Turkey (Tuik, 2017). The pepper is not only consumed in its dried, raw form, but it is also processed and manufactured as pepper paste, sauce, or spices. The nutritionally rich Capia pepper belongs to the group of red sweet peppers. These peppers have extremely low saturated fat, cholesterol and sodium content with a very high vitamin $\mathrm{A}$, vitamin $\mathrm{C}$, vitamin $\mathrm{E}$ (alpha-tocopherol), vitamin B and folate content (Hwang et al., 2012).

Maintenance and improvement of the red color of Capia peppers during the harvest and postharvest stages are necessary for raw consumption as well as for their processing. For these reasons, various groups have been engaged in enhancing the red color of the peppers. In one such study, the authors showed that an application of $100 \mathrm{ppm}$ of ethylene followed by three days of storage at $20-25^{\circ} \mathrm{C}$ with $85-90 \%$ relative humidity improved the color of the peppers (Agblor \& Waterer 2001).

Since the Capia peppers have a sub-tropical origin, they require an optimal temperature of $7-10{ }^{\circ} \mathrm{C}$ for proper storage, thereby minimizing the injury caused by chilling at low temperatures. However, at such a high temperature, the peppers become susceptible to fungal infections leading to their rapid decay. Therefore, to prevent such postharvest losses caused by fungal infections, both chemical and non-chemical treatments to the peppers were studied by different researchers. In a study, the effect of black cumin oil, $\mathrm{CaCl}_{2}$ and Semperfresh ${ }^{\mathrm{TM}}$ on fungal proliferation over the surface of red pepper cv. Capia was investigated and it was found that $600 \mathrm{ppm}$ of the black cumin oil successfully reduced the rate of decay of the Capia peppers at $8^{\circ} \mathrm{C}$ storage temperature (Erdoğmuş et al., 2015). Further, different techniques have also been employed to avoid any compromise on the quality of Capia peppers upon storage at higher temperatures.

Ultraviolet irradiation is an alternative to chemical treatments for the reduction of fungal infection leading to the decay of pepper cultivars. Mercier et al. (2001) studied the anti-fungal effect of UV-C radiations on bell pepper, and found that all the tested doses $\left(0.22,0.44,0.88\right.$, or $\left.2.20 \mathrm{~kJ} \cdot \mathrm{m}^{-2}\right)$ of UV-C efficiently decreased the pepper decay caused by Botrytis cinerea Pers.:Fr. (gray mold). In the present study, however, the dose of $0.88 \mathrm{kJm}^{-2}$ was found to be more effective than the other dose. Mercier and colleagues reported that UV-C seemed to chiefly induce the disease resistance in the crop rather than sanitizing it, thus, the UV-C effectively provided resistance to $B$. cinerea in the fruit at various stages of maturity, i.e., from green to red. Similar results were obtained by Vicente et al. (2005) that the peppers (Capsicum annum L. cv. Zafiro) possessing 90\% red color, when treated with UV-C light $\left(7 \mathrm{~kJ} \mathrm{~m}^{-2}\right)$ and stored at $10^{\circ} \mathrm{C}$ for 18 days showed the reduced decay of the peppers.

The UV-C treatment is known to improve the quality of peppers as well. In order to extend the storage life of the peppers, UV-C irradiation could be employed in combination with different edible coatings. Abbasi et al. (2015) used different doses of UV-C ( $254 \mathrm{~nm}, 3$ and $5 \mathrm{~min}$ ) along with various edible coatings (Aloe gel: 1.5 and 2.5\%, cinnamon oil: 0.30 and $0.40 \%$ and 
chitosan: 1 and 1.5\% doses) so as to observe the delayed changes in the quality of the peppers. Post UV-C treatment, the peppers were stored at $8 \pm 1{ }^{\circ} \mathrm{C}$ with $80-85 \% \mathrm{RH}$ for 24 days and it was found that the UV-C application for 5 min with $1.5 \%$ Aloe gel delayed the changes in firmness, titratable acidity (TA), levels of ascorbic acid, soluble solids content (SSC) and the fruit color development. Moreover, the weight loss, electrolyte leakage, and disease incidence were also lowered at these conditions.

Due to chilling injury, the storage life of the peppers is short and thus, these were stored at a higher temperature, however, the storage duration was minimized because of the risk of fungal infection. Therefore, additional conditions have been used for the storage of the peppers at lower temperatures, such as a brief UV-C treatment that has shown a reduction in the chilling injury (CI) (Cuvi et al., 2011). It was reported that the occurrence of $\mathrm{CI}$ in the UV-C treated peppers was significantly lower than the untreated fruits upon storage for more than 14 days. Furthermore, the authors demonstrated that the UV-C exposure prevents $\mathrm{CI}$ and weight loss in the red peppers, which might be associated with an increased activity of antioxidant enzymes.

Various treatments, except UV-B irradiation, have been used in order to enhance the storage life of the peppers at low temperatures. Thus, the present study intended to investigate the effect of different doses of UV-B irradiation on the quality of peppers.

\section{Materials and methods}

\subsection{Plant material}

Capia peppers (Capsicum annuum L. cv. Capia) were grown in the greenhouse at Arslanbey Vocational School, in Kocaeli University, during the production period of the year, 2016. Peppers were harvested when the surface color of peppers was completely red, followed by immediate transport to the laboratory. The intact peppers that had no signs of any disease or disorder, and were homogenously red in color were selected. The peppers were thoroughly washed with tap water and dried for $15 \mathrm{~min}$ at room temperature. Thereafter, the peppers were subjected to UV-B treatment, packaged, and stored in cold room for the next 49 days.

\subsection{UV-B radiation treatments}

The UV-B radiation device consists of two banks of three stainless-steel reflectors with unfiltered germicidal emitting lamps (TL $40 \mathrm{~W} / 12$ RS Philips, Holland) that are located $30 \mathrm{~cm}$ above and $30 \mathrm{~cm}$ below the radiation vessel. Prior to the use, the lamps were allowed to be stabilized by turning them 'on' for at least $15 \mathrm{~min}$. The peppers were placed between the radiation lamps over a tray for UV-B exposure. The irradiations were performed in the cold room at $5{ }^{\circ} \mathrm{C}$ to avoid the increase in temperature during the treatments. The UV-B measurements were recorded by a radiometer to determine the spectral irradiance of the bare lamp (Kasim \& Kasim, 2015). The peppers were UV-B irradiated for 15 (UV-B 15; $4.46 \mathrm{~kJ} \mathrm{~m}^{-2}$ ) and $30 \mathrm{~min}$ (UV-B 30; $8.93 \mathrm{~kJ} \mathrm{~m}^{-2}$ ), while the untreated peppers served as controls for the study.

\subsection{Packaging and storage conditions}

Post irradiation, three Capia peppers, as 3 replicates, were placed into polystyrene foam dishes having a size of $225 \times 140 \times 30 \mathrm{~mm}$ and wrapped in polyethylene (PE) film. The packaged peppers were stored at $5 \pm 1{ }^{\circ} \mathrm{C}$ temperature with $90-95 \%$ relative humidity. During the 49 days storage period, both qualitative and quantitative analyses were done at intervals of every 15 days.

\subsection{Color measurements}

Color measurements ( $\mathrm{L}^{*}, \mathrm{a}^{*}$, and $\mathrm{b}^{*}$ values) were performed using a chromometer, CR-400 (Konica Minolta, Inc. Osaka, Japan) that is equipped with illuminant D65 and $8 \mathrm{~mm}$ aperture for illumination and measurement. The instrument was calibrated with a white reference tile $\left(L^{*}=97.52, a^{*}=-5.06, b^{*}=3.57\right)$ prior to the measurements. The $\mathrm{L}^{*}(0=$ black, $100=$ white $)$, $\mathrm{a}^{*}(+$ red, - green $)$, and $\mathrm{b}^{*}(+$ yellow, - blue $)$ color coordinates were determined according to the CIE Lab coordinate color space system (Radzevičius et al., 2014). Hue angle $\left(\mathrm{h}^{\circ}=\tan -1\left(\mathrm{~b}^{*} / \mathrm{a}^{*}\right)\right.$ when $\mathrm{a}^{*}>0$ and $\mathrm{b}^{*}>0$ or $\mathrm{h}^{\circ}=180^{\circ}+\tan -1\left(\mathrm{~b}^{*} / \mathrm{a}^{*}\right)$ when $\mathrm{a}^{*}<0$ and $\left.\mathrm{b}>0\right)$ was calculated from the $a^{*}$ and $b^{*}$ values. The percentage of the rate of color change, $\mathrm{L}, \mathrm{a}$, and $\mathrm{h}^{\circ}$ values was calculated relative to the initial values.

\subsection{Decay rate (\%) and intensity}

The decay of peppers during the storage was determined by the percent rate of decayed peppers to the total percent of the peppers. The foremost parameter to be measured was the decay percentage before the start of all other tests. Decay intensity was determined using $1-5$ scale. Where 0 indicated no decay, 1 : decay area $<1 \mathrm{~cm}^{2}, 2$ : decay area $1-3 \mathrm{~cm}^{2}, 3$ : decay area $3-5 \mathrm{~cm}^{2}, 4$ : decay area $5-7 \mathrm{~cm}^{2}, 5$ : decay area $>7 \mathrm{~cm}^{2}$.

\subsection{Respiration rate $\left(\mathrm{mLCO}_{2} \mathrm{~kg}^{-1} \mathrm{~h}^{-1}\right)$}

Respiration rate of peppers was measured using the closed system method. The peppers were placed into glass jars of the total volume of $1.7 \mathrm{~L}$ and to ensure complete air tightness the lids were firmly closed by wrapping its mouth with cellophane. The gas samples were taken at regular intervals with the help of a needle of the $\mathrm{CO}_{2} / \mathrm{O}_{2}$ gas analyzer (Mocon Pack Chec 325) inserted through a rubber septum at the center of the lid. The respiration rates of the peppers were calculated by the equation (Equation 1) mentioned below.

Respiration rate $\left(\mathrm{mLCO}_{2} \mathrm{~kg}^{-1} \mathrm{~h}^{-1}\right)=\frac{\left(\mathrm{V}_{\mathrm{j}}-\mathrm{V}_{\mathrm{f}}\right) \times \mathrm{CO}_{2} \% \times 10}{\mathrm{t} \times \mathrm{G}}$

where $V_{i}$, Volume of the glass jar $(L) ; V_{f}$ Volume of the fruit placed into the jar (L); $\mathrm{CO}_{2}$, Measured carbon-di-oxide from the jar (\%); G, Weight of the fruits placed into the jar (kg); t: The time elapsed after jar was closed.

\subsection{Electrolyte leakage measurement}

Electrolyte leakage (EL) was measured in the slices of the test peppers. Distilled water was used for washing as well as immersion of test sample slices and conductivity was measured 
$2 \mathrm{~h}$ after immersion. Total electrolyte conductivity of the pepper slices was measured after they had been frozen and thawed. EL was calculated as the percentage of the conductivity after $2 \mathrm{~h}$ (Ayala-Zavala et al., 2008).

\subsection{Total soluble solids (TSS)}

TSS were determined for each sample fruit as four replicates at $20^{\circ} \mathrm{C}$ by Atago DR-A1 digital refractometer (Atago Co. Ld., Japan) and expressed as percent values (\%) (Ilić et al., 2015).

\subsection{Loss of weight}

The weight of the samples in triplicates was recorded on the day of harvest and after the designated sampling dates. The loss in weight was calculated using the following formula (Equation 2):

Weight loss $(\%)=(\mathrm{Wi}-\mathrm{Ws} / \mathrm{Wi}) \times 100$

where $\mathrm{Wi}=$ initial weight; Ws = weight at sampling period (Kasim \& Kasim, 2016).

\subsection{Statistical analysis}

The experiments were conducted in a completely randomized design with a minimum of three replicates per treatment per sampling date. The data were analyzed by application of the ANOVA test and differences between mean values were determined using Duncan's multiple range test. The results were denoted to be significant when $P<0.05$.

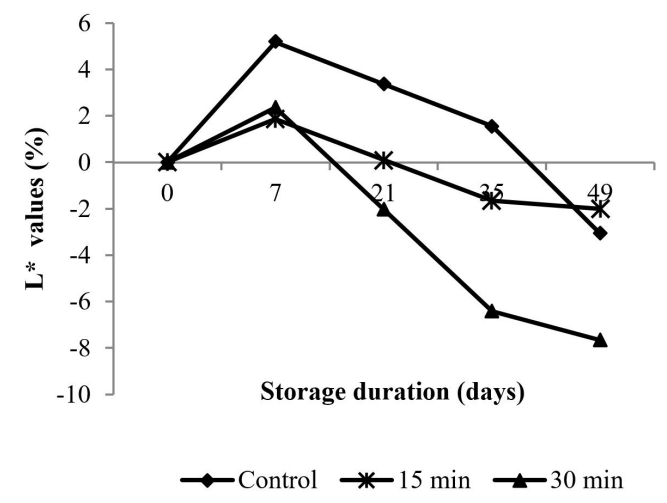

Figure 1. $L^{*}$ values of Capia peppers during the storage.

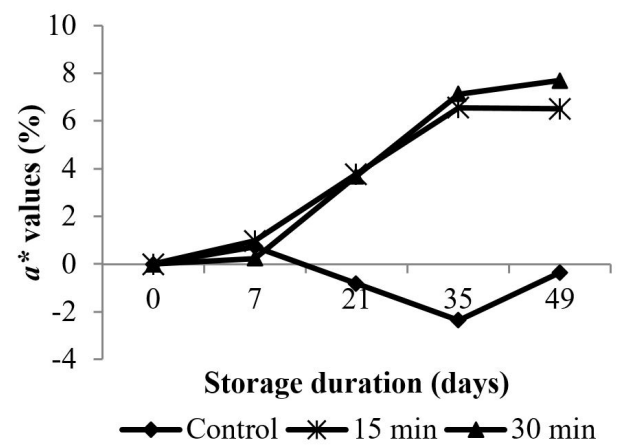

\section{Results and discussion}

\subsection{Color $L^{\star}$ values}

Percent change rates of $\mathrm{L}^{\star}$ values (\%) of the samples in all the treatments increased (Figure 1) for the first seven days of the storage and, $\mathrm{L}^{*}$ values of control samples were higher than the samples in the other two UV irradiation groups. The difference in the storage time was also statistically significant $(\mathrm{p}<0.05)$. However, the $\mathrm{L}^{*}$ values for both the treatment groups started to decrease, thereafter and continued to do so, until the end of the storage period. Whereas this decrease was less in the control group than the UV-B treated groups. Although the high $\mathrm{L}^{*}$ values represent brightness, but these also indicate a reduction in the intensity of the red color. Therefore, it could be said that the high $\mathrm{L}^{*}$ values of the control group indicated a decrease in the red color intensity of the samples. Therefore, it could also be suggested that the UV-B treatments caused an increase in the red color of peppers due to their low $L^{*}$ values. It was found in a previous study that the UV-B treatments caused an increase in the $\mathrm{L}^{*}$ values of tomatoes (Kasim \& Kasim, 2015); however, in the present study, the UV-B-irradiated peppers showed opposite effect, i.e., here the $L^{*}$ values of the red peppers decreased post-UV-B treatment.

\section{$3.2 a^{*}$ and $\mathrm{Hue}\left(h^{\circ}\right)$ values}

Percent change rates of $a^{\star}$ and $\mathrm{h}^{\circ}$ values are shown in Figure 2. The $\mathrm{a}^{*}$ values of peppers under both UV-B treatments increased during the storage, which indicates that the red color of UV-B treated peppers was improved. In addition, the differences in the storage time were found to be statistically significant $(\mathrm{p}<0.05)$. The percentage change rate of $\mathrm{a}^{*}$ values in UV-B treated and the control groups was significantly different during the storage. While the $\mathrm{a}^{*}$ values of the peppers treated with UV-B increased during storage, the values declined for the control group peppers. UV applications cause stress in products, and also fruits can change their metabolic activities in response. For example, in products exposed to UV radiation, the amount of dry matter is increasing (Kasim \& Kasim, 2015). Similarly, in the present study, in ultraviolet applied peppers, red color increased in response to stress, but no such increase was observed in the control group. So, this result was compatible with previous studies. In addition, the difference between the UV-B treated groups and the control group was statistically significant $(\mathrm{p}<0.05) . \mathrm{h}^{\circ}$ values increased during storage like $\mathrm{a}^{\star}$ values (Figure 2 ). This increase was the

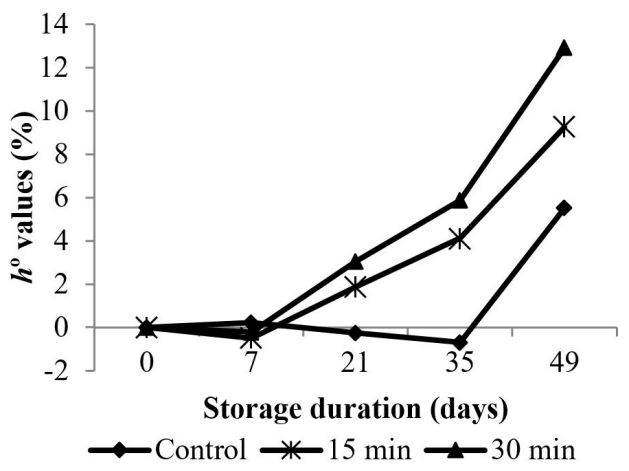

Figure 2. Changes of color $a^{\star}$ and $h^{O}$ values of Capia peppers during storage. 
highest in UV-B 30 than both UV-B 15 and control group, also differences among the treatments were significant, statistically $(\mathrm{p}<0.05)$. In all treatments group $\mathrm{h}^{\circ}$ values increased sharply at the day of 35 . This increasing could be due to senescence. Because pepper is not a climacteric fruit, the color of fruit is more darker at the senescence period compared to early development stage.. Cuvi et al. (2011) determined that the exposure to UV-C $\left(10 \mathrm{~kJ} \mathrm{~m}^{-2}\right)$ did not alter the fruit color; however, in our study, especially in the UV-B $30\left(8.93 \mathrm{~kJ} \mathrm{~m}^{-2}\right)$ treatment group, the red color of peppers improved. Thus, it can be said that the UV-B treatment is effective for the enhancement of the red color than the UV-C treatment. Our finding is supported by a previous study in which the hue angle of UV-B treated tomatoes was found to be high (Kasim \& Kasim, 2015).

\subsection{Decay rate (\%) and intensity}

In the present study, Capia peppers were stored at $5 \pm 1{ }^{\circ} \mathrm{C}$ throughout the period of 49 days, and during the first 21 days, no signs of decay on the pepper body were observed. Post 21 day of the storage, the rate as well as the intensity of the decay of the peppers in both the treatment groups increased. The highest elevation was observed by the UV-B 30 treatment, followed by the control group and the UV-B 15 (Figure 3). Moreover, the variation observed in the UV-B 30, UV-B 15 and the control groups was statistically significant $(\mathrm{p}<0.05)$. It is well known that the UV radiation treatments decrease the decay of the irradiated product via induction of defense mechanism and also by an increase in the levels of polyamines in the cell membrane (Charles \& Arul, 2007). However, in contrast, exposure to high doses of ultraviolet rays could be deleterious for the cell membrane. Thus, in the present analysis, we show that the higher dose of UV-B used herein causes damage to the Capia peppers as compared to the lower dose, as evident by the slow decay rate and lower intensity of the peppers. A higher level of weight loss and electrolyte leakage of the peppers in the UV-B 30 group further supports our analysis.

\subsection{Respiration rate ( $\left.\mathrm{mL} \mathrm{CO} \mathrm{Cg}_{2}^{-1} \mathrm{~h}^{-1}\right)$}

Respiration rate of Capia peppers decreased till 21 days post storage, and thereafter the rate increased. This increase continued till the end of the storage duration (Figure 4).

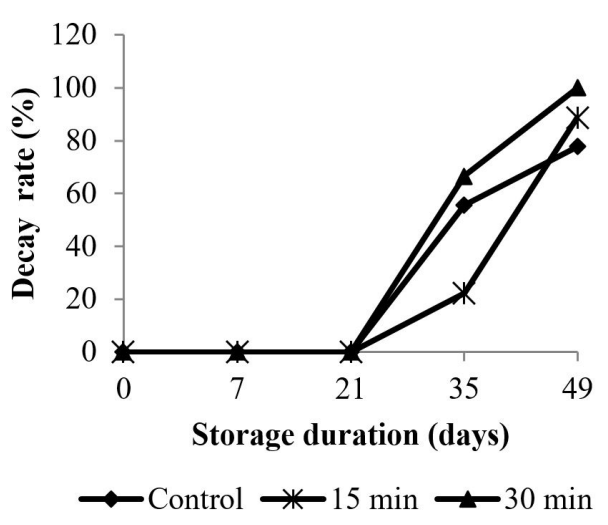

The difference between the respiration rate in context to storage time was found to be statistically significant $(\mathrm{p}<0.05)$; however, the variations among different groups were not statistically valid. Respiration rate is vital for the metabolism of crops. Therefore, the effect of its increase or decrease on the product was studied. Although the respiration rate of peppers was low at the beginning till 21 days post storage due to cold conditions, it increased in the later phase, especially, in the UV-B 30 and the control groups. The respiration rate of fruit is firsty increase at the early development stage of fruit, but with the maturation is started to increase, then decrease during the senescence period. In the present study the respiration rate was decrease for 21 days, and after then increased, in all treatments group. This increase could be due to cell damage elongation of the storage period. Because, the respiration rate was the highest the samples in UV-30 treatment, followed by control group.Therefore, it can be said that there was a simultaneous start of the cell membrane damage, electrolyte leakage and the increased rate of decay in the control and the UV-B 30 treated groups.

\subsection{Electrolyte leakage}

Electrolyte leakage (EL) from Capia peppers is depicted in Figure 5. The samples from both the UV- B treated groups showed increased EL during the entire storage period. At the end of the storage period, maximum EL was observed from the peppers in the UV-B 30 (34.46) group, while the control group samples showed minimum EL (27.40), with all the values being statistically significant $(\mathrm{p}<0.05)$. Promyou \& Supapvanich (2012) reported that the UV-C exposure, especially at high dose $\left(6.6 \mathrm{~kJ} \mathrm{~m}^{-2}\right)$ decreased EL in contrast to the unexposed crops and attributed such findings to the induction of biological stress and defense mechanism in the product post UV-C irradiation. Similar results were obtained by Vicente et al. (2005) after the analysis of UV-C treatment to red pepper. However, in our present work, we found that UV- B exposed red peppers showed a higher EL as compared to the control group peppers; EL from the UV-B 30 samples was higher than the UV-B 15 samples. Furthermore, the observation that the rate and intensity of pepper decay were highest in the UV-B 30 group supports our understanding that the UV-B treatment causes tissue damage.

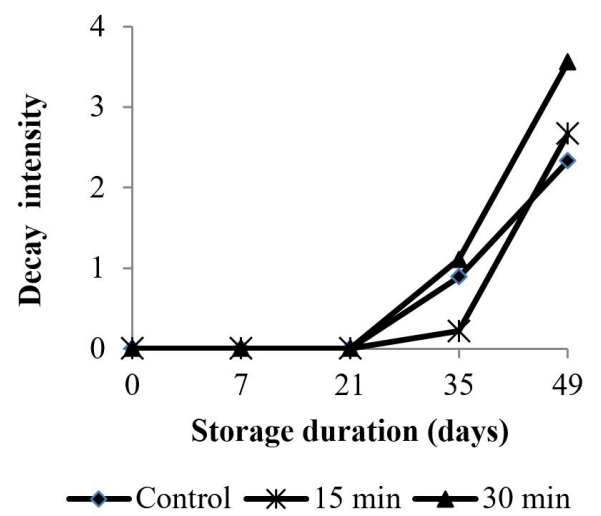

Figure 3. Decay rate and intensity of Capia peppers during storage. 


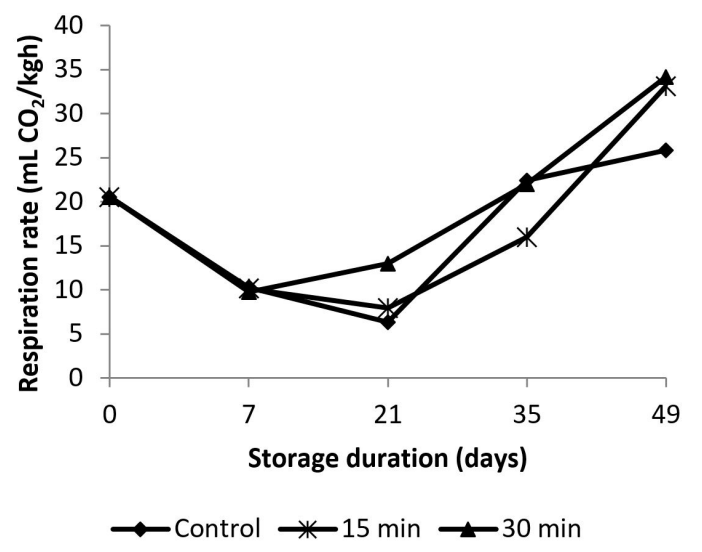

Figure 4. Respiration rate of Capia peppers during storage.

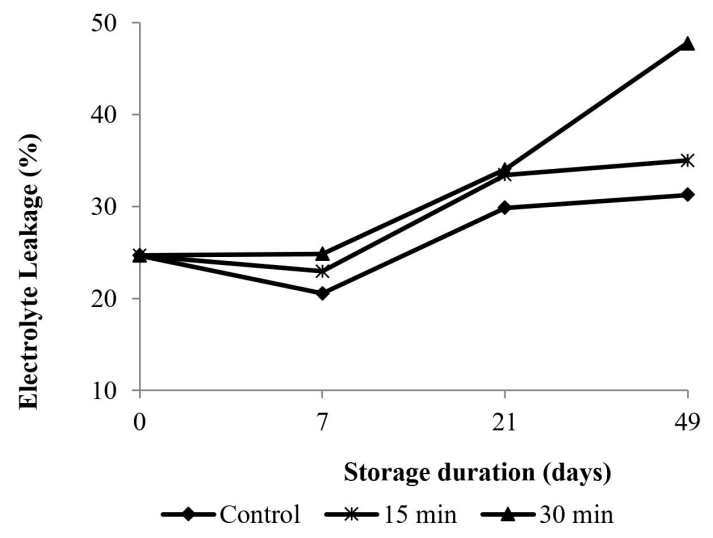

Figure 5. Changes in electrolyte leakage of Capia peppers during storage.

\subsection{Total soluble solids}

Soluble carbohydrates are most important for the postharvest storage duration as these are required during respiration. Therefore, minimizing the utilization of the soluble solids would be beneficial to provide extended storage life to crops. The ultraviolet irradiation is known to cause surface disinfection, as well as, stimulate the defense mechanism of the product. In our current work, we found that during the storage period, the TSS content of samples in both the UV-B groups was lower as compared to the control group peppers (Figure 6), however, this data were statistically insignificant $(\mathrm{p}<0.05)$. In this context, the exposure of UV-B for 30 min was more effective than the 15 min treatment. The TSS content of samples in the control, UV-B 15 and UV-B 30 groups, i.e., 49 days, was 4.52\%, 5.27\%, and $5.85 \%$, respectively. at the end of the storage period.

\subsection{Weight loss}

The storage of Capia peppers at $5 \pm 1{ }^{\circ} \mathrm{C}$ for 49 days led to an increase in weight loss of the peppers in the UV- B treated groups (Figure 7). The percentage of weight loss increased from $0.48 \%$ to $3.51 \%$, however, it did not reach the level at which the peppers could not be sold. It has been reported that 4 to $6 \%$ of weight loss in fresh commodities lead the fruits to shrivel and of low commercial value (Wills et al., 2007). Our study demonstrated

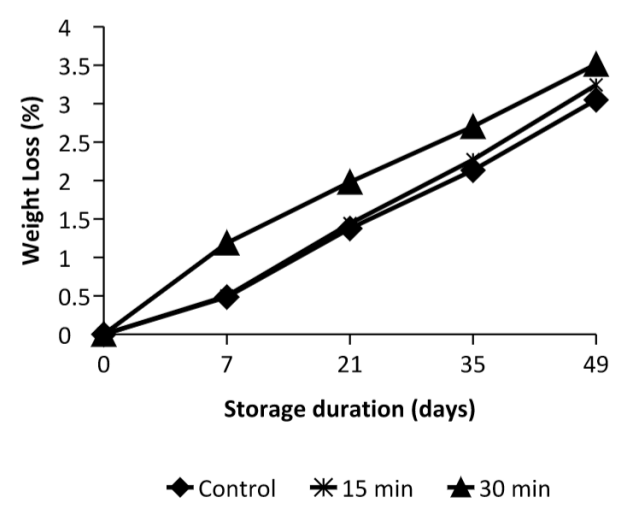

Figure 6. Changes in TSS content of Capia peppers during storage.

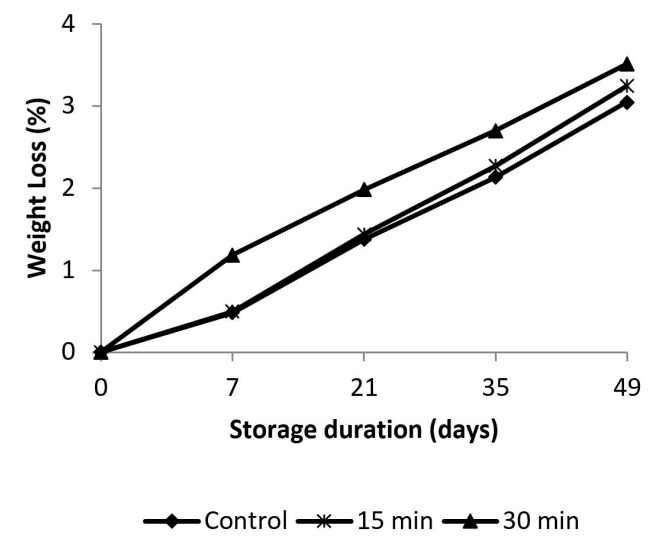

Figure 7. Weight loss of Capia peppers during storage.

a maximum weight loss of $3.51 \%$ of the peppers. The highest percentage of weight loss was observed in case of UV-B exposure for $30 \mathrm{~min}$ followed by $15 \mathrm{~min}$ of UV-B treatment and the untreated group. However, the difference between the UV-B treatment groups was insignificant. Cuvi et al. (2011) reported that the lower doses $\left(10 \mathrm{~kJ} / \mathrm{m}^{-2}\right)$ of UV-C radiations led to a reduced amount of weight loss in contrast to the higher doses, at which the weight loss was higher. Accordingly, our results also show a lower amount of weight loss at the lower dose $(15 \mathrm{~min})$ of UV-B than that of the higher UV-B dose (30 min). Further, as expected, the weight loss of samples in the control group was the lowest. Therefore, it can be stated that the UV-B treatment at both the doses caused damage to the fruit skin and also increased the rate of respiration of the peppers; the respiration rate was higher in the UV-B 30 group as compared to the UV-B 15 or the control groups. These observations, further, were relate to the higher amount of weight loss observed in the test samples, with the UV-B irradiation.

\section{Conclusions}

In the present study, the effect of ultraviolet-B (UV-B) irradiation at two different doses on the color and decay rate of Capia peppers was analyzed. The peppers to be studied were harvested at the full red ripe stage and were subjected to UV-B radiation on two sides 
and stored for the next 49 days. We found that the red color of Capia peppers improved by both the doses of UV-B treatment as compared to the controls. Since, the peppers are chiefly supplied as pepper sauces or dried pepper, etc.; the color of these peppers is a significant property, as the color of the processed product affects the consumer choice. Thus, improvement in the color leads to a better quality raw material for further processing. Moreover, for fresh pepper consumption also, the color of the pepper is vital, as a uniform red colored pepper has a high sale rate. In addition, the shelf life of peppers is short because of the chilling injury caused by storage at low temperature. Here, we report that the UV-B 15 treatment reduced the decay rate and the intensity of peppers that were stored at chilling temperature. Consequently, our findings suggest that the UV-B treatment at doses of $4.46 \mathrm{~kJ} \mathrm{~m}^{-2}$ is effective for the improvement of the color and also reduction of the decay of peppers.

\section{Acknowledgements}

This research has been funded by Kocaeli University, Project Number: 2014/075.

\section{References}

Abbasi, N. A., Ashraf, S., Ali, I., \& Butt, S. J. (2015). Enhancing storage life of bell pepper by UV-C irradiation and edible coatings. Pakistan Journal of Agricultural Sciences, 52(2), 403-411.

Agblor, S., \& Waterer, D. (2001). Peppers: post-harvest handling and storage: fact sheet. Canada: Canada-Saskatchewan Irrigation Diversification Centre.

Ayala-Zavala, J. F., Del-Toro-Sanchez, L., Alvarez-Parrilla, E., \& GonzalezAguilar, G. A. (2008). High relative humidity in-package of freshcut fruits and vegetables: advantage or disadvantage considering microbiological problems and antimicrobial delivering systems. Journal of Food Science, 73(4), 41-47. PMid:18460138. http://dx.doi. org/10.1111/j.1750-3841.2008.00705.x.

Charles, M. T., \& Arul, J. (2007). UV treatment of fresh fruits and vegetables for improved quality: a status report. Stewart Postharvest Review, 3(3), 1-8. http://dx.doi.org/10.2212/spr.2007.3.6.

Cuvi, M. J. A., Vicente, A. R., Concellón, A., \& Chaves, A. R. (2011). Changes in red pepper antioxidants as affected by UV-C treatments and storage at chilling temperatures. Lebensmittel-Wissenschaft + Technologie, 44(7), 1666-1671. http://dx.doi.org/10.1016/j. lwt.2011.01.027.
Erdoğmuş, A.Ö., Kaynaş, K. \& Kaya, S. (2015). The effects of some postharvest applications on storage quality of red pepper (Capsicum annuum L. cv. Capia). Çanakkale Onsekiz Mart Üniversitesi Ziraat Fakültesi Dergisi, 3(2), 45-53.

Hwang, I. G., Shin, Y. J., Lee, S., Lee, J., \& Yoo, S. M. (2012). Effects of different cooking methods on the antioxidant properties of red pepper (Capsicum annuum L.). Preventive Nutrition and Food Science, 17(4), 286-292. PMid:24471098. http://dx.doi.org/10.3746/ pnf.2012.17.4.286.

Ilić, Z. S., Milenković, L., Šunić, L., \& Fallik, E. (2015). Effect of coloured shade-nets on plant leaf parameters and tomato fruit quality. Journal of the Science of Food and Agriculture, 95(13), 2660-2667. PMid:25389124. http://dx.doi.org/10.1002/jsfa.7000.

Kasim, M. U., \& Kasim, R. (2015). Postharvest UV-B treatments increased fructose content of tomato (Solanum lycopersicon L. cv. Tayfun F1) harvested at different ripening stages. Food Science and Technology, 35(4), 742-749. http://dx.doi.org/10.1590/1678-457X.0008.

Kasim, M. U., \& Kasim, R. (2016). The effects of calcium chloride and ascorbic acid treatment on ready-to-use carrot shreds. Journal of Life Science, 10, 7-15. http://dx.doi.org/10.17265/1934-7391/2016.01.002.

Mercier, J., Baka, M., Reddy, B., Corcuff, R., \& Arul, J. (2001). Shortwave ultraviolet irradiation for control of decay caused by Botrytis cinerea in Bell Pepper: induced resistance and germicidal effects. Journal of the American Society for Horticultural Science, 126(1), 128-133.

Promyou, S., \& Supapvanich, S. (2012). Effect of ultraviolet-C (UVC) illumination on postharvest quality and bioactive compounds in yellow bell pepper fruit (Capsicum annuum L.) during storage. African Journal of Agricultural Research, 7(28), 4084-4096.

Radzevičius, A., Viškelis, P., Viškelis, J., Karkleliene, R., \& Juškevičienè, D. (2014). Tomato fruit color changes during ripening on vine. International Journal of Biological, Biomolecular, Agricultural, Food and Biotechnological Engineering, 8(2), 112-114.

Tuik (2017, August 19). Capia pepper statistics. Retrieved from http:// www.tuik.gov.tr/PreTablo.do?alt_id=1001

Vicente, A. R., Pineda, C., Lemoine, L., Civello, P. M., Martinez, G. A., \& Chaves, A. R. (2005). UV-C treatments reduce decay, retain quality and alleviate chilling injury in pepper. Postharvest Biology and Technology, 35(1), 69-78. http://dx.doi.org/10.1016/j. postharvbio.2004.06.001.

Wills, R. B. H., Mcglasson, W. H., Grahan, D., \& Joyce, D. C. (2007). Postharvest: an introduction to the physiology and handling of fruit, vegetables and ornamentals. Wallingford: New South Wales University Press. 